Japanese Journal of Physiology, 29, 85-98, 1979

\title{
The Dynamics of Contraction in the Guinea Pig Taenia Coli
}

\author{
Hidenobu Mashima, Takao OKada, and Hiroshi OKuyama \\ Department of Physiology, School of Medicine, Juntendo \\ University, Tokyo, 113 Japan
}

\begin{abstract}
Tension-length, load-velocity and tension-extension relations were studied in the taenia coli muscle of the guinea pig weighing 0.25 $0.5 \mathrm{~kg}$ at $36-37^{\circ} \mathrm{C}$. The muscle was relaxed by $10^{-6} \mathrm{~g} / \mathrm{ml}$ adrenaline and stimulated by a strong $\mathrm{AC}$ field. The tension-length diagram was far wider than that of the skeletal muscle and sufficient tension was generated at longer lengths than $1.8 L_{m}$, where $L_{m}$ is the optimal length at which the maximum tension, $F_{m}$, is generated. The developed force per unit cross-sectional area was almost unchanged between 1.2-2.0 $L_{m}$. Average of the maximum forces was $2.2 \mathrm{~kg} / \mathrm{cm}^{2}$. Load-velocity curves obtained at various isometric forces at $L_{m}$ coincided with each other, if the velocity was plotted against the relative force. All curves can be expressed by a single force-load-velocity equation,

$$
(P+A)(v+b)=b(F+A), \quad A=\left(F / F_{m}\right) a,
$$

where $P$ is the load, $F$ the isometric force, $v$ the velocity, $a$ and $b$ are constants. The maximum velocity per unit muscle length was constant, irrespective of the muscle length. The compliance of the series elastic component, that is, the slope of the tension-extension curve, did not depend on the isometric force but decreased with decreasing muscle length. The internal lengthening of the series elastic component by the full isometric tension was about $3 \%$ of the muscle length at $L_{m}$.
\end{abstract}

There are some difficulties for the study on the dynamics of contraction in mammalian smooth muscles. One of them is the inability to standardize the experimental conditions, particularly to determine the optimum length, at which the maximum tension is developed, because of the spontaneous activity and the plasticity in contractility. Another difficulty is the variety of muscles showing widely different electrical and mechanical properties according to the animals or organs to which they belong. For these reasons, only several studies have been done on the mechanical properties of the guinea pig taenia coli. MASHIMA and Yoshida (1965) examined the effect of muscle length on the spontaneous contraction and the development of tension produced by strong alternating current stimu-

Received for publication October 12, 1978

真島英信，岡田隆夫，奥山博司 
lation in the taenia coli. ÅBERG and AXELSSON (1965) stimulated the taenia coli with a high potassium solution and studied the load-velocity relation at the reference length, which was the inactive in situ length. Gordon and SiEgman (rabbit, 1971) and Lowy and Mulvany (1973) studied the mechanical properties of the taenia coli at a lower temperature $\left(22-23^{\circ} \mathrm{C}\right)$ in order to depress the spontaneous activity. These studies were performed in different animals, using different methods of stimulation and temperatures.

The present study is aimed to clarify the fundamental mechanical properties of the guinea pig taenia coli, such as the length-tension and load-velocity relations of the contractile component as well as the tension-extension relation of the series elastic component, using the same electrical stimulation, in order to disclose the special characteristics in the contraction dynamics of the smooth muscle.

\section{METHODS}

A guinea pig weighing $0.25-0.5 \mathrm{~kg}$ was anesthetized with ether, the abdominal cavity was quickly opened after decapitation and the caecum was exposed. Two points, usually $20 \mathrm{~mm}$ apart, were marked on the taenia coli and tied off with a thin cotton thread. The strip was dissected, taking care to exclude the mucous and submucous tissues underneath the taenia coli by properly lifting the ligatures. Immediately after dissection the strip was mounted in the test chamber $(5 \times 3 \times 1.5$ cm) filled with $15 \mathrm{ml}$ of Krebs' solution, which contained $\mathrm{NaCl} 118 \mathrm{~mm}, \mathrm{NaHCO}_{3}$ $25 \mathrm{mM}, \mathrm{KCl} 2.5 \mathrm{mM}, \mathrm{MgSO}_{4} 1.2 \mathrm{mM}, \mathrm{KH}_{2} \mathrm{PO}_{4} 1.2 \mathrm{~mm}, \mathrm{CaCl}_{2} 2.5 \mathrm{~mm}$ and glucose $10 \mathrm{~mm}$; the $\mathrm{pH}$ was 7.4. The solution was aerated with a $95 \% \mathrm{O}_{2}$ and $5 \% \mathrm{CO}_{2}$ gas mixture throughout the experiment and the temperature of the solution was maintained at $36-37^{\circ} \mathrm{C}$ by a thermoelectric heat regulator. After mounting, the muscle length was adjusted to the in situ length and the surrounding tissues as much as possible were carefully removed under a binocular microscope.

The arrangement for mechanical measurement was similar to that described by MASHIMA et al. (1972). One end of the strip was penetrated at the ligature by the tip of the needle of the isometric lever and tied tightly under a binocular microscope. The tension was conveyed by the lever to the anodal pin of an RCA 5734 tube. The other end was also tied to the tip of the long arm of the rectangular isotonic lever, which was made of light wood, the long arm is $10 \mathrm{~cm}$ and the short arm is $1.5 \mathrm{~cm}$ in length and $400 \mathrm{mg}$ in weight, and the load was hung on the short arm at $1.0 \mathrm{~cm}$ from the pivot. The movement of the lever was detected photoelectrically. The tension and displacement of the muscle were displayed simultaneously on a cathod-ray oscilloscope or an ink-writing rectigraph (frequency characteristics: $80 \mathrm{~Hz}$ at $20 \mathrm{~mm}$ peak-to-peak). The compliance of the whole mechanical system was about $5 \mu \mathrm{m} / \mathrm{g}$. The muscle length was varied with an accuracy of $0.1 \mathrm{~mm}$ by moving the isometric lever which was mounted on a sliding scale with a vernier. 
A piston-type velocity controller was attached to the isotonic lever to make a controlled release for the measurement of shortening velocity of the contractile component, in order to minimize the damped oscillation of the shortening curve immediately after release. The quick release by a moving coil vibrator (Ling 201) was also used, in order to measure the tension change of the series elastic component immediately after a known amount of quick release. The isotonic lever was connected to the vibrator, the movement of which was controlled by an electronic negative feedback network. For a step input the movement of the vibrator was quickly compensated without overshoot and the moving velocity was $5-7 \mathrm{~cm} / \mathrm{sec}$.

A pair of platinum foil electrodes were placed on opposite walls of the chamber in parallel with, or vertical to the muscle in order to effect transverse or longitudinal electric field stimulation (AC at $50-100 \mathrm{~Hz}$ ). The intensity of the stimulus was adjusted so as to generate a maximum contraction. Longitudinal field stimulation was more effective as described by SPERELAKIs (1962), and usually the maximum stimulation was $15-20 \mathrm{~V} / \mathrm{cm}$ in transverse, or $6-10 \mathrm{~V} / \mathrm{cm}$ in longitudinal field in peak-to-peak voltage between electrodes. The same tension responses could be obtained repeatedly every $2 \mathrm{~min}$ without fatigue for several hours.

\section{RESULTS}

\section{Tension-length relation}

The preparation was mounted between the isometric and isotonic levers and the length was adjusted to the in situ length of $20 \mathrm{~mm}$. In order to stop spontaneous contractions, $10^{-6} \mathrm{~g} / \mathrm{ml}$ of adrenaline were added to the bath (MASHIMA and Yoshida, 1965). The peak tension of the atonic muscle was identical to that of spontaneous contractions. The muscle then was stimulated isometrically by the maximum stimulus for 3-5 sec. The stimuli were repeated at intervals of $2 \mathrm{~min}$ at various muscle lengths. The muscle length at which the maximum isometric tension, $F_{m}(\mathrm{~g})$, was developed, was referred to as the $100 \%$ length or the optimal length, $L_{m}(\mathrm{~cm})$. There were two types of muscles, even if the muscle was dissected after applying $10^{-6} \mathrm{~g} / \mathrm{ml}$ adrenaline solution immediately after the laparotomy. Type A was the muscle whose optimal length was near the in situ length, but type B muscle generated the maximum tension at a length far shorter than the in situ length, usually $25 \%$ and sometimes $50 \%$ shorter.

One of the tension-length diagrams for the type A muscles is shown in Fig. 1. The in situ length was $20 \mathrm{~mm}$. When the muscle was stretched from 8 to $22 \mathrm{~mm}$ by 2-mm steps the developed tension increased rapidly, but began to decrease on further stretching to $26 \mathrm{~mm}$ (curve 1). However, when the muscle was shortened again to $20 \mathrm{~mm}$, the developed tension increased more than before (curve 2). Thus, the maximum tension $\left(F_{m}=11.5 \mathrm{~g}\right)$ and the optimal length $\left(L_{m}=20 \mathrm{~mm}\right)$ were determined. No more increase in tension was observed on further stretching or shortening of the muscle. Afterwards, the muscle was stretched beyond $26 \mathrm{~mm}$. 


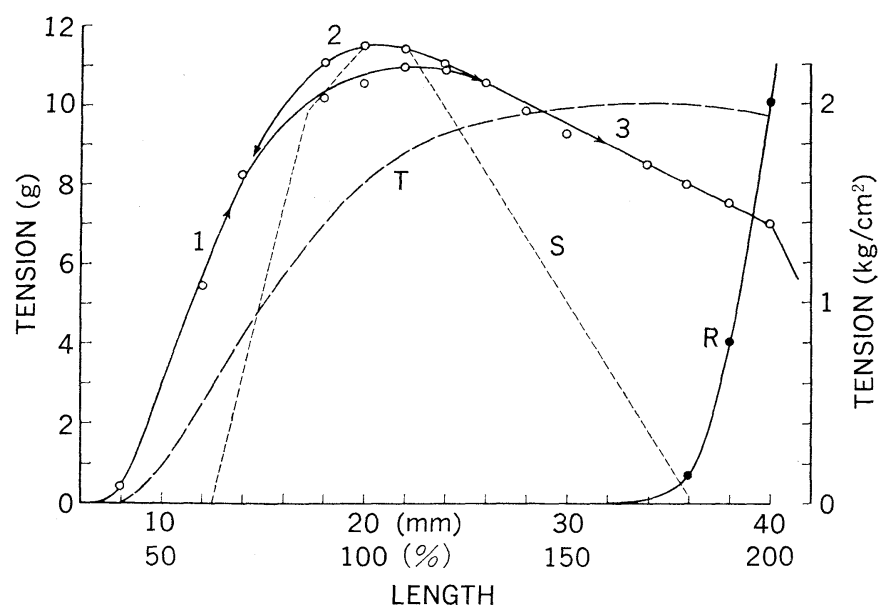

Fig. 1. Tension-length relation for the isometric tetanus of taenia coli. The developed tension was measured in the order of $1 \rightarrow 2 \rightarrow 3$. $T$ : tension per unit cross-sectional area, $\mathrm{R}$ : resting tension, $\mathrm{S}$ : relation for the skeletal muscle (Gordon et al., 1966), $36^{\circ} \mathrm{C}$.

The developed tension decreased almost in proportion to the increase in length (curve 3). At lengths of more than $30 \mathrm{~mm}$, the resting tension increased gradually with increasing muscle length, but at lengths of more than $36 \mathrm{~mm}$, the resting tension increased markedly (curve R). For the resting tension as well as the developed tension, marked hysteresis was observed with a change in length. Furthermore, the steady resting tension corresponding to a new length was attained quickly after one or two contractions, otherwise a long time was required for the resting tension to reach a new steady level after a change in muscle length. Still, if the muscle was stretched to the length where the resting tension is more than the developed tension the tension decreased irreversibly and only a smaller tension was developed when the muscle was shortened again to the previous length. Probably such an over-stretching injures the muscle cell. Therefore, the experiment usually was done within the reversible length range. In type B muscle, the maximum tension was observed at shorter lengths than the in situ length. However, the shape of the tension-length diagram was similar if the developed tension was plotted against the relative length of $L_{m}$. The dotted curves in Fig. 1 illustrates the tension-length relation for the frog skeletal muscle described by GoRdon et al. (1966). It is remarkable that the tension-length diagram for the taenia coli is far wider than that for the skeletal muscle. The taenia coli can generate sufficient tension at lengths beyond $180 \% L_{m}$, where no tension can be developed in skeletal muscle.

The maximum tension did not depend on the excised length of the muscle strip. For example, the same maximum tension was observed in three strips of 10, 20 and $30 \mathrm{~mm}$ in situ length which were dissected from the same taenia coli. Moreover, when the $20-\mathrm{mm}$ strip was tied with thread at the center, each half also 
developed the same tension as that of the whole strip.

2. The maximum force per unit cross-section

After the experiment, the muscle was transferred into another bath, in which the muscle could be rotated around the long axis. The largest and smallest diameters $\left(d\right.$ and $\left.d^{\prime}\right)$ of the muscle strip at the in situ length were measured at the thinnest portion under a binocular microscope. The cross-sectional area of the strip was estimated as $\pi d d^{\prime} / 4$. The cross-sectional areas at the other muscle lengths can be calculated assuming that the volume of the strip is constant. The average value of the force per unit cross-section, $F\left(\mathrm{~g} / \mathrm{cm}^{2}\right)$, thus obtained was $2.0 \pm 0.25$ $\mathrm{kg} / \mathrm{cm}^{2}$ at $L_{m}$ in 11 preparations. The cross-sectional area was also calculated from the weight of the muscle divided by the length. The weight was measured after pressing the muscle from both sides with filter papers. The average value of $F\left(\mathrm{~g} / \mathrm{cm}^{2}\right)$ determined by this calculation was $1.7 \pm 0.12 \mathrm{~kg} / \mathrm{cm}^{2}$ in 15 preparations. This is about $15 \%$ smaller than the former value, probably because of the difficulty in thoroughly removing the extracellular fluid in the latter method. Hence, the former value is considered to be more correct.

The developed tension per unit cross-section was calculated and plotted against the muscle length as seen in Fig. 1, curve T. It is noteworthy that the active force per unit cross-section does not show much change (less than $10 \%$ ) between 120 $200 \%$ length. Moreover, it is remarkable that the maximum force per unit cross-section is generated at around $170 \%$ length and only $80 \%$ of this maximum force is generated at $L_{m}$. Taking account of this fact, the maximum value of $F\left(\mathrm{~g} / \mathrm{cm}^{2}\right)$ would be greater than the value at $L_{m}$ by about $20 \%$, that is, $2.2 \mathrm{~kg} / \mathrm{cm}^{2}$.

\section{Force-load-velocity relation}

During the plateau of the maximum isometric contraction at $L_{m}$ the controlled release was made and the shortening velocity, $v$, against the load, $P$, was measured (Fig. 2). The load-velocity curve thus obtained was hyperbolic (Fig. 3, curve 1), obeying Hill's equation,

$$
(P+a)(v+b)=b\left(F_{m}+a\right),
$$

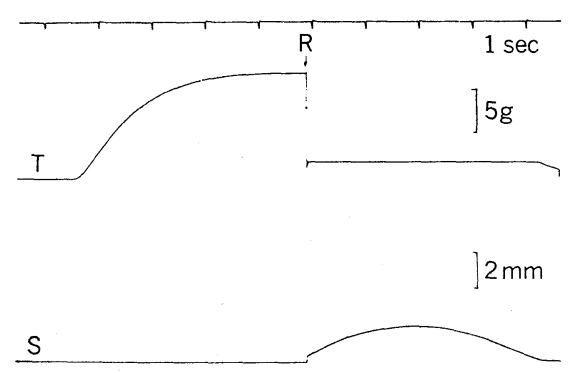

Fig. 2. Tension (T) and shortening (S) curves during the controlled release. The muscle was tetanized isometrically and the release was made at $\mathrm{R}$ in the plateau phase with $2 \mathrm{~g}$ load. $36^{\circ} \mathrm{C}$. 
where $a$ is the heat constant and $b$ the rate constant of energy liberation. The values of constants for the curve 1 are $F_{m}=12.5 \mathrm{~g}, L_{m}=20 \mathrm{~mm}, a / F_{m}=0.099$, $b=0.097 \mathrm{~cm} / \mathrm{sec}$ and the maximum velocity $V_{\max }=F_{m}(b / a)=0.98 \mathrm{~cm} / \mathrm{sec}$. The average values of the dynamic constants in 10 preparations are $a / F_{m}=0.11$ and $b=0.056 L / \sec$ (normalized by the muscle length, $L$ ) and $V_{\max }=0.53 L / \sec$ (Table 1).

Table 1. Dynamic constants at the optimal length.

\begin{tabular}{lcccc}
\hline \multicolumn{1}{c}{ Muscle } & $\begin{array}{c}F_{m} \\
\left(\mathrm{~kg} / \mathrm{cm}^{2}\right)\end{array}$ & $a / F_{m}$ & $\begin{array}{c}b \\
(L / \mathrm{sec})\end{array}$ & $\begin{array}{c}V_{\max } \\
(L / \mathrm{sec})\end{array}$ \\
\hline $\begin{array}{l}\text { Taenia coli } \\
\left.\text { (guinea-pig, } 36^{\circ} \mathrm{C}\right)\end{array}$ & $2.0-2.2$ & 0.11 & 0.056 & 0.53 \\
\hline $\begin{array}{l}\text { Skeletal muscle* } \\
\left.\text { (frog, } 10^{\circ} \mathrm{C}\right)\end{array}$ & $1.8-3.0$ & 0.25 & 0.90 & 3.6 \\
\hline
\end{tabular}

* From Mashima et al. (1972).

The effect of isometric force on the load-velocity curve under the same initial length was examined in two ways. Giving the controlled release at a certain instant during the rising phase of the isometric contraction, the shortening velocity caused by a smaller tension than $F_{m}$ was measured. In the other experiments the controlled release was made during a submaximal steady tetanic tension. The tetanic tension of depolarized taenia coli decreased with decreasing stimulus intensity as described by SPERELAKIS (1962). Raising the external $\mathrm{K}^{+}$concentration to $8-10 \mathrm{~mm}$, the various submaximal plateau tensions were easily induced.

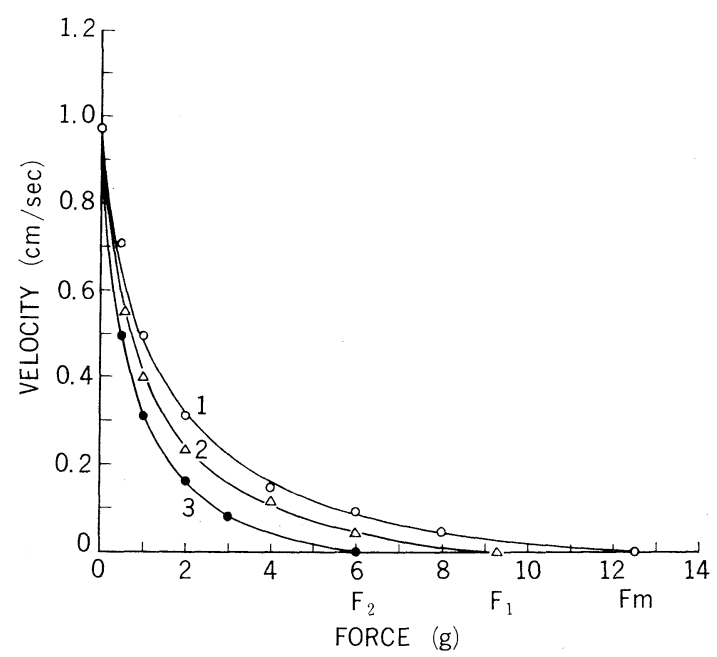

Fig. 3. Load-velocity curves obtained at various isometric forces but at the same initial length of $L_{m}$. Curve 1: isometric force was $F_{m}(=12.5 \mathrm{~g})$, curve 2: $F_{1}(=9.2 \mathrm{~g})$, curve 3: $F_{2}(=6 \mathrm{~g})$. Initial length: $20 \mathrm{~mm}, a / F_{m}=0.099, b=0.097 \mathrm{~cm} / \mathrm{sec}, V_{\max }=0.98 \mathrm{~cm} / \mathrm{sec}$, $36^{\circ} \mathrm{C}$. 
The results obtained by both methods, however, were identical. One of the results is also shown in Fig. 3, in which the load-velocity points were measured for the reduced isometric tensions, $F_{1}=9.2 \mathrm{~g}$ and $F_{2}=6 \mathrm{~g}$. These points were also on the hyperbolic curve with the dynamic constants of $a_{1}, b_{1}$ and $a_{2}, b_{2}$, respectively. The curves 2 and 3 in Fig. 3 were drawn by calculation using the dynamic constants of $a_{1} / F_{1}=a_{2} / F_{2}=a / F_{m}(=0.099)$ and $b_{1}=b_{2}=b(=0.097 \mathrm{~cm} / \mathrm{sec})$. The measured load-velocity points were satisfactorily fitted with these calculated curves, converging to the common $V_{\max }(=0.98 \mathrm{~cm} / \mathrm{sec})$. Namely, the constant $b$ does not alter with a change in the isometric force, $F$, but the value of $a$ (at $F_{m}$ ) changes in proportion to $F$, if the initial length is kept constant. In other words, all curves coincide with each other if the velocity is plotted against the relative force. Accordingly, Eq. (1) can be generalized for all isometric forces $\left(F \leqq F_{m}\right)$ as follows:

or

$$
(P+A)(v+b)=b(F+A), \quad A=\left(F / F_{m}\right) a
$$

$$
F\left(1+\frac{a}{F_{m}}\right) \frac{v}{v+b}=F-P \equiv F_{v}
$$

where $F_{v}$ is the viscous-like force or the velocity-dependent force-loss during isotonic shortening. The fact that $F_{v}$ is a linear function of $F$ suggests that the unit force in the cell is working against the unit viscosity (MASHIMA et al., 1972).

The lengthening velocity against the larger loads than the maximum force also was measured. The lengthening velocity measured at the initial length of $L_{m}$ was about $4 \% V_{\max }$ at the load of $1.2 F_{m}$ and $12 \% V_{\max }$ at $1.3 F_{m}$, but it was difficult to determine the lengthening velocity against a load larger than $1.3 F_{m}$, because the understroke of the lengthening curve after the release became too large. Probably the contractile component of the smooth muscle 'gives' against such a heavy load, although $1.3 F_{m}$ is far smaller than the 'giving' load in striated muscles (MASHIMA et al., 1972; MASHIMA, 1977).

\section{Effect of the initial length on the load-velocity relation}

The load-velocity curves at various initial lengths were examined. One of the results is shown in Fig. 4. Curve 1 is obtained at the initial length, $L=10 \mathrm{~mm}$, and the isometric force, $F=12.5 \mathrm{~g}$, curve 2 at $15 \mathrm{~mm}$ and $11.5 \mathrm{~g}$, curve 3 at $20 \mathrm{~mm}$ and $10 \mathrm{~g}$ and curve 4 at $25 \mathrm{~mm}$ and $8 \mathrm{~g}$. In this muscle, $L_{m}$ is $10 \mathrm{~mm}$ and the experiment was done at lengths longer than $L_{m}$. Anyhow, all curves are hyperbolic and the dynamic constants for these curves are shown in Table 2.

It is noted that the constant $a / F$ increased only slightly, and the absolute value of $b(\mathrm{~cm} / \mathrm{sec})$ considerably with an increase in the initial length. However, the value of $b(L / \mathrm{sec})$ per unit muscle length is almost constant regardless of the initial length. Eventually, the maximum velocity per unit length, $V_{\max } / L$, shows almost no change, at least between the initial length of $15-25 \mathrm{~mm}$. In other words, the shortening velocity per unit muscle length does not depend on the initial length. 


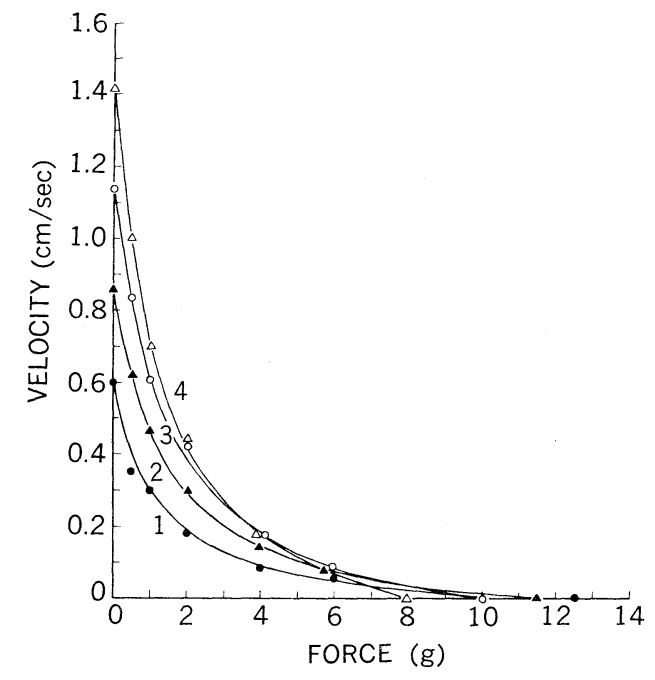

Fig. 4. Load-velocity curves obtained at various muscle lengths. Curve 1: initial length and isometric force are $10 \mathrm{~mm}$ and $12.5 \mathrm{~g}$, curve $2: 15 \mathrm{~mm}, 11.5 \mathrm{~g}$, curve $3: 20 \mathrm{~mm}, 10 \mathrm{~g}$, curve $4: 25 \mathrm{~mm}, 8 \mathrm{~g}, 36^{\circ} \mathrm{C}$.

Table 2. Dynamic constats at different initial lengths.

\begin{tabular}{ccccccc}
\hline & & \multicolumn{2}{c}{$b$} & & \multicolumn{2}{c}{$V_{\max }$} \\
$(\mathrm{cm})$ & $a / F$ & $(\mathrm{~cm} / \mathrm{sec})$ & $(L / \mathrm{sec})$ & & $(\mathrm{cm} / \mathrm{sec})$ & $(L / \mathrm{sec})$ \\
\hline 1.0 & 0.12 & 0.060 & 0.06 & & 0.50 & 0.50 \\
1.5 & 0.12 & 0.105 & 0.07 & & 0.86 & 0.57 \\
2.0 & 0.14 & 0.160 & 0.08 & & 1.14 & 0.57 \\
2.5 & 0.16 & 0.225 & 0.09 & & 1.42 & 0.57 \\
\hline
\end{tabular}

However, when the initial length is much shorter than $L_{m}$, both $b$ and $V_{\max }$ slightly decreased.

5. Tension-extension relation of the series elastic component at various initial lengths

During the plateau of isometric contraction, a small amount (less than $0.7 \mathrm{~mm}$ ) of quick release was made by means of the moving coil oscillator with a negative feedback network and the fall in tension at the end of the release was recorded, using the rectigraph (Fig. 5) and the oscilloscope simultaneously. Varying the amounts of release, the relation between the release distance and the tension fall was measured, that is, the tension-extension curve of the series elastic component (SEC) was obtained. The experiments were repeated at various initial lengths. One of the results is shown in Fig. 6 . In this muscle, $F_{m}$ is $15.4 \mathrm{~g}\left(=2.0 \mathrm{~kg} / \mathrm{cm}^{2}\right)$ at $L_{m}=15 \mathrm{~mm}$, and curve 2 was obtained at $L_{m}$. Curve 1 was obtained at $F=14.2 \mathrm{~g}, L=10 \mathrm{~mm}$, curve 3 at $F=12.1 \mathrm{~g}, L=20 \mathrm{~mm}$ and curve 4 at $F=10.8 \mathrm{~g}, L=24 \mathrm{~mm}$. Obviously, the compliance of SEC decreases 


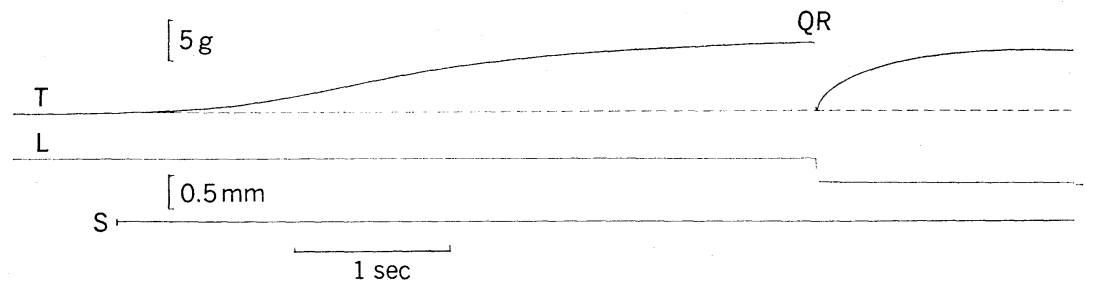

Fig. 5. Measurement of the tension change at a given amount of quick release during the plateau of isometric tetanus. T: tension curve, L: length curve, S: stimulation (AC $100 \mathrm{~Hz}$ ), QR: the instant of quick release, muscle length: $20 \mathrm{~mm}$, amount of release: $0.3 \mathrm{~mm}, 37^{\circ} \mathrm{C}$.

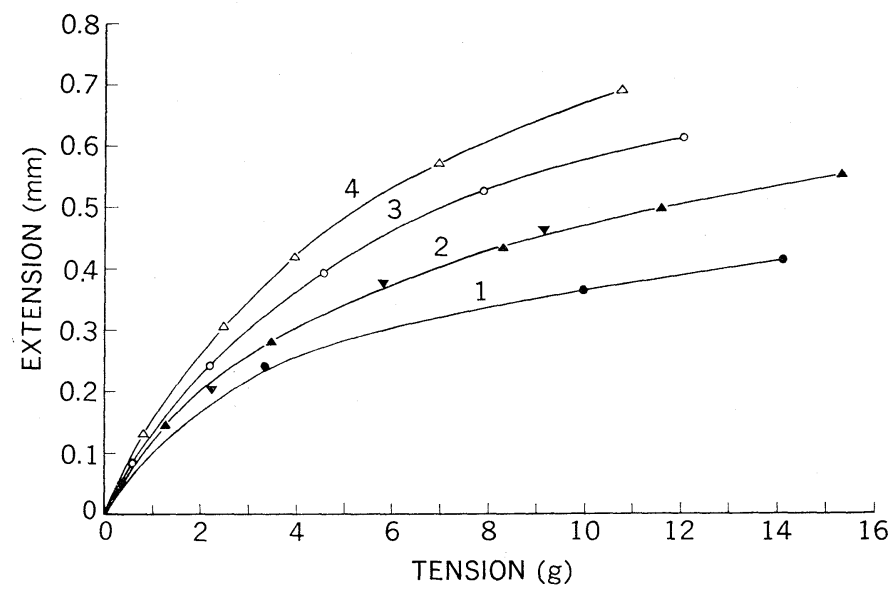

Fig. 6. Tension-extension curves at various muscle lengths obtained by the method shown in Fig. 5. Curve 1: muscle length is $10 \mathrm{~mm}$, curve 2:15 mm, curve 3: $20 \mathrm{~mm}$, curve 4: $24 \mathrm{~mm}$. In curve $2,(\Delta)$ : isometric force is $15 \mathrm{~g},(\boldsymbol{\nabla}): 9 \mathrm{~g} . \quad 36^{\circ} \mathrm{C}$.

with a decrease in the muscle length. However, if the initial length is unchanged, the compliance does not depend on the isometric force as shown in Fig. 6, curve 2 (black triangles and reversed black triangles). The lengthening of the series elastic component when the tension rose to its full isometric value was about $3 \%$ of the muscle length at $L_{m}$ in 5 preparations.

Secondly, the controlled release method was used to obtain the load-extension curve of SEC, and the amount of shortening immediately after the release against a certain load was determined graphically. Extending a line tangential to the following shortening curve caused by the contractile component, the intersection of this line and the axis formed by the instant of release determines the amount of shortening (JEWELL and WILKIE, 1958). The results were similar to those obtained by the first method, but it was difficult to determine the curves at smaller loads and impossible to measure at no load by the second method. 

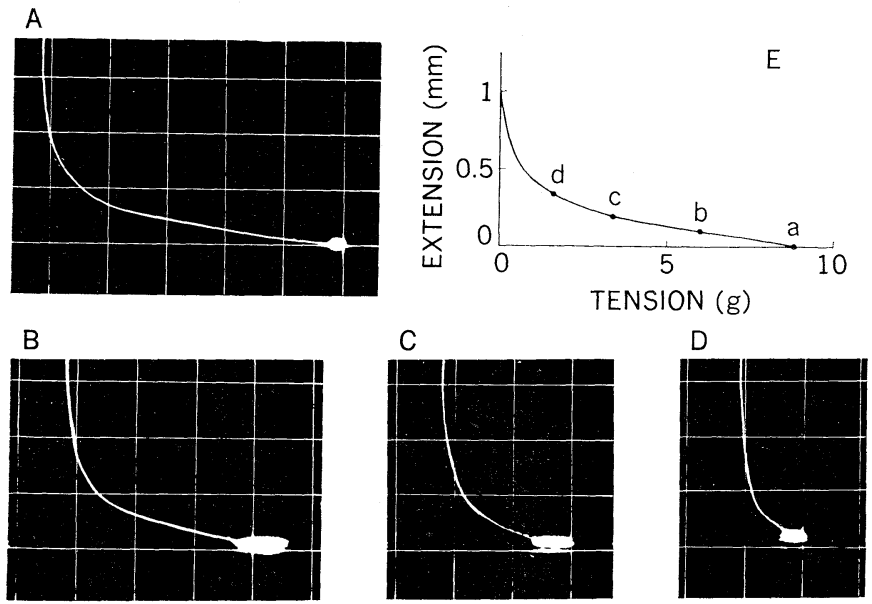

Fig. 7. $\mathrm{X}-\mathrm{Y}$ records of tension-extension curves during controlled release at various isometric forces. A: isometric force is $8.9 \mathrm{~g}, \mathrm{~B}: 6 \mathrm{~g}, \mathrm{C}: 3.4 \mathrm{~g}, \mathrm{D}: 1.6 \mathrm{~g}, \mathrm{E}$ : traces of curves in $A, B, C$ and $D$. The curve in $A$ is traced from point $a$, the curve in $B$ from $b$, the curve in $\mathrm{C}$ from $\mathrm{c}$ and the curve in $\mathrm{D}$ from $\mathrm{d}$. Scales are indicated in E. Muscle length: $20 \mathrm{~mm}$, release velocity: $6.5 \mathrm{~cm} / \mathrm{sec}, 37^{\circ} \mathrm{C}$.

Thirdly, the direct X-Y record of the tension-extension relation during the shortening immediately after the controlled release was displayed on cathod ray oscilloscope. The velocity of release was controlled to $6-7 \mathrm{~cm} / \mathrm{sec}$. The X-Y records obtained at various isometric forces and at the same initial length are shown in Fig. 7. All curves can be completely superimposed on one another. Thus, it was confirmed that the compliance of the series elastic component did not depend on the isometric force when the initial length was kept constant. In the third method, it was difficult to determine the exact lengthening of SEC corresponding to the full isometric tension, because the curve gradually approaches the ordinate of zero tension due to viscosity. Therefore, the internal lengthening was estimated to be about $5 \%$ of the muscle length at $L_{m}$. It would be better to take the value determined by the first method as the internal lengthening of SEC.

\section{DISCUSSION}

The optimal length, $L_{m}$, of the taenia coli is near the in situ length in type A muscle or about $25 \%$ shorter than it in type B muscle, as has been suggested by MASHIMA and Yoshida (1965). This difference can be explained by the plastic property of the smooth muscle and the restricted length change caused by the surrounding tissues. If the muscle is in the contracted length at the time of dissection, the in situ length would be near the $L_{m}$. However, when the muscle is in the relaxed length or stretched by adjacent contracting parts, the in situ length must be far longer than the $L_{m}$. Even if adrenaline solution is applied to the taenia 
coli before dissection, the muscle length does not change to the relaxed length unless it is stretched, although the spontaneous discharges are abolished. It was frequently observed that, when the adrenaline-relaxed taenia coli was stretched or shortened, a preceding contraction was necessary before obtaining both the steady resting and developed tensions at the new length. This plastic property may be based on the intracellular rearrangement of the contractile filaments.

In the striated muscle cell, the contractile units (sarcomeres) are always in series and never slide against each other, and the force of the unit decreases as its length increases in the length range longer than $L_{m}$. In the taenia coli muscle, however, it has been proposed by SMALL (1977) that the contractile unit involving many contractile apparatuses is attached at each end to the cell membrane and the contractile apparatus proper is composed of thick and thin filaments. Of course, how the shearing interaction between the filaments takes place is still unknown, but the lack of bipolarity on the smooth muscle myosin filaments and the absence of actin-associated structures equivalent to the $\mathrm{Z}$ band of striated muscle (SMALL, 1977) suggest that the myosin filaments can passively slide within a certain limit depending on the cell length, and the amount of active sliding between the filaments is considerably greater than in skeletal muscle. As shown in Fig. 1, the active force per unit cross-section is almost constant at longer lengths than $L_{m}$, especially from 1.2 to $2.0 L_{m}$. This fact also implies that the contractile filaments are able to slide passively on each other according to the initial length. This property may also explain the marked hysteresis and wider tension-length diagram as shown in Fig. 1 and the extremely long-lasting creep or plasticity of the taenia coli described by GrEvEN and HoHORST (1975). Besides the taenia coli, the wider working length has also been observed in other mammalian smooth muscles: for example, in uterine muscles (CSAPO, 1955; SCHOFIELD and WOOD, 1964) and in various vascular muscles (SPEDEN, 1960; SPARKS and BoHR, 1962; DoBRIN, 1973; Herlihy and MurPhy, 1973). Marked hysteresis in the resting and developed tensions was also pointed out by WeIss et al. (1972) in cat ureteral muscle. After all, the ability to change the arrangement of myofilaments depending on the cell length is considered to be a common property in smooth muscles.

The maximum force, $F_{m}\left(\mathrm{~g} / \mathrm{cm}^{2}\right)$, of the taenia coli is $2.2 \mathrm{~kg} / \mathrm{cm}^{2}$ in the present study and this is almost comparable with that of skeletal muscle (Table 1). This value is similar to the results of previous studies ( $\AA$ BERG and AXELSSON, 1965; Lowy and MulvaNy, 1973) obtained by various stimulations and at various temperatures in the taenia coli. According to GABELLA (1976a), the contracture tension of taenia coli produced by carbachol was $2.51-5.13$ (mean, 4.16 ) $\mathrm{mN} / \mathrm{cm}^{2}$ and temperature changes in the range $23-38^{\circ} \mathrm{C}$ had little effect on the maximal force. Furthermore, he described that when allowance was made for the extracellular space (about $32 \%$ ), for the non-muscular cells (about $5 \%$ ) and for the noncontractile material (about 10\%) in the specimen, the maximum force was about $7.34 \mathrm{mN} / \mathrm{cm}^{2}$ of contractile material and almost twice as large as in skeletal muscle,

Vol. 29, No. 1, 1979 
and suggested that such a large force by the smooth muscle was partly explained by the lateral attachment of contractile units to sites along the entire cell length. Thus, the force generated in the contractile units can be summed up in parallel as well as in series. Moreover, it is possible that a similar mechanism of force summation works not only between the contractile units within the cell but also between the cells. This double summation system by the series and parallel networks of force transmission may be the cause of the large force of smooth muscle, although the myosin content of the smooth muscle is estimated to be only about $1 / 5$ of striated muscle (MurPHY et al., 1974).

The load-velocity curve for the taenia coli is hyperbolic, conforming to the results described by Åberg and AXeLSSON (1965), Gordon and Siegman (1971) and Lowy and Mulvany (1973). Not only in the taenia coli but also in other smooth muscles the load-velocity curves are hyperbolic, such as in rabbit uterine muscle (CSAPO, 1955), in dog respiratory airway muscle (STEPHENS et al., 1969), cat intestinal muscle (Meiss, 1971) and rat vascular muscle (PeIPER et al., 1975). It has also been shown in the present study that the load-velocity curves obtained with various isometric forces can be described by a single force-load-velocity equation (Eq. (2)), if the initial length is kept constant. This relation has already been found in frog skeletal muscle (MASHIMA et al., 1972) and frog ventricular muscle (MASHIMA, 1977). As this equation suggests that the unit force is working against the unit viscosity, it is likely that the contractile mechanism similar to the filament sliding by the cross-bridges in the striated muscle could also work in the smooth muscle, although no evidence has yet been presented.

The maximum shortening velocity per unit muscle length, $V_{\max } / L$, is constant independent of the initial muscle length at least between $L_{m} \pm 25 \%$, conforming to the result described by GoRdon and SiEgman (1971). This fact also is explained by assuming the rearrangement of myofilaments depending on the initial length. The value of $V_{\max }$ in the present study is $0.53 \mathrm{~L} / \mathrm{sec}$, about $1 / 40$ of the skeletal muscle, assuming that the temperature coefficient is about 2 (Table 1).

The internal lengthening of the series elastic component (SEC) when the tension rises to the full isometric value is about $3 \%$ of the muscle length. This value is almost equal to that of the frog skeletal muscle (CAvagna, 1970). From the fact that the compliance of SEC did not depend on the isometric force, it is certain that most of the SEC does not reside in the force generator. The SEC on the taenia coli may reside mainly in the intercellular network of connective tissues but a part of it may also reside in a cytoskeletal framework within the muscle cell, including $10 \mathrm{~nm}$ filaments and dense bodies as suggested by SMALL (1977). In the present study the compliance of the SEC increased with increasing muscle length. This fact suggests that the intracellular and intercellular non-contractile structures can be transformed gradually against some viscosity from a more parallel to a more series network when the muscle is stretched. In fact, GABELLA (1976b) observed that collagen fibrils ran parallel to the stretched cells but they ran obliquely and 
transversely around the shortened cells, probably due to the characteristics of the cell surface. However, if the contraction occurs, the new state corresponding to the new length will be accomplished more quickly. This rearrangement of noncontractile fibrils as well as the contractile filaments, must play an important role in determining the appearance of the viscous and plastic nature depending on the length change in smooth muscle.

\section{REFERENCES}

ÅberG, A. K. G. and Axelsson, J. (1965) Some mechanical aspects of an intestinal smooth muscle. Acta Physiol. Scand., 64: 15-27.

Cavagna, G. A. (1970) The series elastic component of frog gastrocnemius. J. Physiol., 206: 257-262.

Csapo, A. (1955) The mechanism of myometrial function and its disorders. In: Modern Trends in Obstetrics and Gynaecology, Butterworth, London, pp. 20-49.

DoBRIN, P. B. (1973) Influence of initial length on length-tension relationship of vascular smooth muscle. Am. J. Physiol., 225: 664-670.

Gabella, G. (1976a) The force generated by a visceral smooth muscle. J. Physiol., 263: 199_ 213.

Gabella, G. (1976b) Structural changes in smooth muscle cells during isotonic contraction. Cell Tissue Res., 170: 187-201.

Gordon, A. M., Huxley, A. F., and Julian, F. J. (1966) The variation in isometric tension with sarcomere length in vertebrate muscle fibres. J. Physiol., 184: 170-192.

Gordon, A. R. and Siegman, M. J. (1971) Mechanical properties of smooth muscle. I. Lengthtension and force-velocity relations. Am. J. Physiol., 221: 1243-1249.

Greven, K. and Hоноrst, B. (1975) Creep after loading in relaxed and contracted ( $\mathrm{KCl}$ or $\mathrm{K}_{2} \mathrm{SO}_{4}$ depolarized) smooth muscle (taenia coli of the guinea pig). Pflügers Arch., 359: 111125.

HerLihy, J. T. and Murphy, R. A. (1973) Length-tension relationship of smooth muscle of the hog carotid artery. Circ. Res., 33: 275-283.

JeweLl, B. R. and WiLKIE, D. R. (1958) An analysis of the mechanical components in frog's striated muscle. J. Physiol., 143: 515-540.

Lowy, J. and MulvanY, M. J. (1973) Mechanical properties of guinea pig taenia coli muscles. Acta Physiol. Scand., 88: 123-136.

Mashima, H. (1977) The force-load-velocity relation and the internal load of tetanized frog cardiac muscle. Jpn. J. Physiol., 27: 485-501.

Mashima, H., Akazawa, K., Kushima, H., and Fuji, K. (1972) The force-load-velocity relation and the viscous-like force in the frog skeletal muscle. Jpn. J. Physiol., 22: 103-120.

Mashima, H. and Yoshida, T. (1965) Effect of length on the development of tension in guineapig's taenia coli. Jpn. J. Physiol., 15: 463-477.

MeIss, R. A. (1971) Some mechanical properties of cat intestinal muscle. Am. J. Physiol., 220: 2000-2007.

Murphy, R. A., Herlihy, J. T., and Megerman, J. (1974) Force-generating capacity and contractile protein content of arterial smooth muscle. J. Gen. Physiol., 64: 691-705.

Peiper, U., LAVEN, R., and EhL, M. (1975) Force-velocity relationships in vascular smooth muscle. Pflügers Arch., 356: 33-45.

Schofield, B. M. and Wood, C. (1964) Length-tension relation in rabbit and human myometrium. J. Physiol., 175: 125-133.

Small, J. V. (1977) Studies on isolated smooth muscle cells: The contractile apparatus. $J$.

Vol. 29, No. 1, 1979 
Cell Sci., 24: 327-349.

Sparks, H. V., Jr. and BoHr, D. F. (1962) Effect of stretch on passive tension and contractility of isolated vascular smooth muscle. Am. J. Physiol., 202: 835-840.

SPEDEN, R. N. (1960) The effect of initial strip length on the noradrenaline-induced isometric contraction of arterial strips. J. Physiol., 154: 15-25.

Sperelakis, N. (1962) Contraction of depolarized smooth muscle by electric fields. Am. J. Physiol., 202: 731-742.

Stephens, N. L., Kroeger, E., and Mehta, J. A. (1969) Force-velocity characteristics of respiratory airway smooth muscle. J. Appl. Physiol., 26 (6): 685-692.

Weiss, R. M., BASSEtT, A. L., and Hoffman, B. F. (1972) Dynamic length-tension curves of cat ureter. Am. J. Physiol., 222: 388-393. 